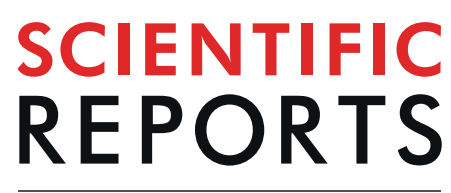

natureresearch

There are amendments to this paper

\title{
OPEN
}

Received: 17 June 2019

Accepted: 15 August 2019

Published online: 06 September 2019

\section{Classification of aggressive and classic mantle cell lymphomas using synchrotron Fourier Transform Infrared microspectroscopy}

Magdalena Kolodziej ${ }^{1}$, Dorota Jesionek-Kupnicka ${ }^{2}$, Marcin Braun ${ }^{2,3}$, Vitaliy Atamaniuk ${ }^{4}$, Sylwia Sloniec ${ }^{4}$, Jozef Cebulski ${ }^{4}$, Marian Cholewa ${ }^{4}$, Janusz Kopczynski ${ }^{5}$, Philip Heraud ${ }^{6,7}$, Mark J. Tobin ${ }^{8}$, Jitraporn Vongsvivut ${ }^{8}$ \& Izabela Zawlik ${ }^{9,10}$

Mantle cell lymphoma (MCL) is regarded as an incurable neoplasm, even to the novel drug strategies. It is known MCL has two morphological variants- classic and aggressive. Aggressive MCL is characterized by a higher mitotic index and proliferation rate, and poor overall survival in comparison to classic subtype. The insight into the detailed biochemical composition of MCL is crucial in the further development of diagnostic and treatment guidelines for MCL patients; therefore Synchrotron radiation Fourier Transform Infrared (S-FTIR) microspectroscopy combined with Principal Component Analysis (PCA) was used. The major spectral differences were observed in proteins and nucleic acids content, revealing a classification scheme of classic and aggressive MCLs. The results obtained suggest that FTIR microspectroscopy has reflected the histopathological discrimination of both MCL subtypes.

Mantle cell lymphoma (MCL) is a mature B-cell lymphoma, which originates from the inner mantle zone and is characterised by elevated expression of cyclin D1 as a result of the 11q13 translocation ${ }^{1}$. MCL diagnosis is based on standard histopathological examination complemented essentially by immunohistochemical staining for CD20, CD5, cyclin D1 and Ki67 and frequently supplemented by broad immunohistochemical panels including SOX11, TP53, p16, C-MYC, molecular analysis of 11q13 translocation and inclusion of clinical parameters, such as lactate dehydrogenase levels and white blood cell counts ${ }^{2,3}$.

MCL is regarded as an incurable neoplasm, and is resistant to novel drug strategies ${ }^{2,4}$; therefore, there is an emerging need for unravelling the biology of this malignancy. It is already known that MCL is a heterogeneous disease and distinct morphological variants have been described. These encompass classic and aggressive (blastoid and pleomorphic) mantle cell lymphomas ${ }^{2-4}$. The classic MCL is composed mainly of small-to-medium sized lymphocytic cells with moderate features of malignancy and displays mantle zone, nodular, or diffuse architecture. The aggressive MCLs, on the other hand, show high malignant features (resembling lymphoblasts in blastoid variant and resembling large, heterogeneous, anaplastic cells in pleomorphic variants). The classic MCL is characterised by lower mitotic index and lower proliferation rate (Ki67/MiB-1 index) in comparison to both aggressive subtypes $^{5}$. The aggressive MCLs have more frequently poor prognostic mutations in TP53 and CDKN2A/B genes in comparison to the classic MCLs ${ }^{6,7}$. Finally, the aggressive MCLs are characterised by a poorer progression-free

${ }^{1}$ Faculty of Medicine, University of Rzeszow, Rzeszow, Poland. ${ }^{2}$ Department of Pathology, Chair of Oncology, Medical University of Lodz, Lodz, Poland. ${ }^{3}$ Postgraduate School of Molecular Medicine, Medical University of Warsaw, Warsaw, Poland. ${ }^{4}$ Faculty of Mathematics and Natural Sciences, University of Rzeszow, Rzeszow, Poland. ${ }^{5}$ Department of Pathology, Holy Cross Cancer Center, Kielce, Poland. ${ }^{6}$ Department of Microbiology \& Monash Biomedical Discovery Institute, Faculty of Medicine, Nursing and Health Sciences, Monash University, Victoria, Australia. ${ }^{7}$ Centre for Biospectroscopy, School of Chemistry, Monash University, Clayton, Australia. ${ }^{8}$ Australian Synchrotron, ANSTO, Clayton, Victoria, Australia. ${ }^{9}$ Centre for Innovative Research in Medical and Natural Sciences, Faculty of Medicine, University of Rzeszow, Rzeszow, Poland. ${ }^{10}$ Department of Genetics, Institution of Experimental and Clinical Medicine, University of Rzeszow, Rzeszow, Poland. Magdalena Kolodziej, Dorota Jesionek-Kupnicka and Marcin Braun contributed equally. Correspondence and requests for materials should be addressed to I.Z. (email: izazawlik@yahoo.com) 
and overall survival, when compared to classic variants and according to current guidelines aggressive MCL patients are allocated into high-risk groups ${ }^{2,5}$.

Although the MCLs classification is well-established with histopathological assessment, the insight into the molecular/biochemical information would be invaluable for a better description of both entities and would be a fundamental proof for the validity of their classification.

Fourier Transform Infrared (FTIR) microspectroscopy offers a novel approach for the assessment of biochemical changes such as healthy and cancerous tissue differentiation and the determination of cancer subtypes without the use of any additional reagents ${ }^{8,9}$. Synchrotron radiation (SR) sources provide bright, broadband infrared light, enabling the analysis of micron-sized samples with higher than the conventional signal to noise than is possible with conventional IR sources ${ }^{10}$. The purpose of the current study was to determine differences between classic and aggressive mantle cell lymphomas using S-FTIR microspectroscopy combined with PCA analysis of the acquired spectroscopic data.

\section{Results}

Histopathological micrographs of control and malignant lymph node tissues, classic and aggressive MCL, are shown in Fig. 1.

FTIR spectral description. Representative absorbance (A) and Extended Multiplicative Scattering Corrected second derivative (B) average spectra of the healthy control and two MCL subtypes are presented in Fig. 2. Since the visual inspection of peak positions on raw spectra was difficult, spectra were transformed into the second derivative to enhance the features of overlapping bands (Fig. 2b). The second derivative spectrum gives a negative value for every band located in the absorbance spectrum and allows for more accurate identification of individual peaks in complex spectra. The averaged spectra of every patient included in the further analysis can be found in Supplementary Figs S1-S4.

The absorbance minima determined for all tissues in the protein region are vibrations of amide I (1700-1630 $\mathrm{cm}^{-1}$ ) and amide II $\left(1580-1500 \mathrm{~cm}^{-1}\right)$ functional groups ${ }^{10-12}$. The peaks localised at $1695 \mathrm{~cm}^{-1}, 1682 \mathrm{~cm}^{-1}$ and $1639 \mathrm{~cm}^{-1}$ are characteristic for aggregated $\beta$-sheet, $\beta$-turn, and $\beta$-sheet structures, respectively ${ }^{11,13}$. Typically, the minimum found at $1655 \mathrm{~cm}^{-1}$ is attributed to $\alpha$-helix structures of amide $\mathrm{I}^{13}$. The $(\mathrm{N}-\mathrm{H})$ bending coupled to $(\mathrm{C}-\mathrm{N})$ symmetric stretching vibrations assigned to amide II are localised at $1571 \mathrm{~cm}^{-1}$ and $1541 \mathrm{~cm}^{-112,14}$. Of note is a peak found at $1515 \mathrm{~cm}^{-1}$, typically attributed to $(\mathrm{C}-\mathrm{H})$ bending vibrations of tyrosine ${ }^{15}$. Of interest are absorbance intensity changes observed for malignant tissues. Both classic and aggressive MCL represents an increase in absorbance intensity noted in peak attributed to $\alpha$-helix $\left(1655 \mathrm{~cm}^{-1}\right)$ structure of amide I, more pronounced in aggressive MCL (Fig. 2b). Absorbance intensity increase noticed in aggressive subtype has also been observed for minima attributed to amide I $\beta$-sheet $\left(1639 \mathrm{~cm}^{-1}\right)$, amide II $\left(1541 \mathrm{~cm}^{-1}\right)$ and tyrosine $\left(1515 \mathrm{~cm}^{-1}\right)$ (Fig. 2b). It was already reported that features associated with an aggressive clinical course of MCL included overexpression of the $\mathrm{p} 53$ protein ${ }^{6}$. This protein plays an important role in the regulatory control of the cell cycle and its mutations have been associated with the progression to more aggressive forms of the disease $\mathrm{e}^{6,16}$.

The absorbance minima found at $1425 \mathrm{~cm}^{-1}$ and $1330 \mathrm{~cm}^{-1}$ are typically responsible for asymmetric and symmetric $\mathrm{CH}_{3}$ and $\mathrm{CH}_{2}$ bending vibrations of lipids and proteins ${ }^{8,10}$. The peak localised at $1404 \mathrm{~cm}^{-1}$ is responsible for $\left(\mathrm{CH}_{3}\right)$ bending vibrations of proteins ${ }^{13}$.

The other prominent peaks occur in the lower wavenumber region. The peak found in control tissue at $1231 \mathrm{~cm}^{-1}$, assignable to asymmetric stretching vibrations of $\mathrm{PO}_{2}^{-}$in $\mathrm{DNA}^{17}$ is shifted towards higher wavenumber by $3 \mathrm{~cm}^{-1}$ and $7 \mathrm{~cm}^{-1}$ in classic and aggressive MCL respectively. Moreover, the absorbance intensity of this peak is increased in aggressive MCL, which coincide with available knowledge about cyclin D1 overexpression ${ }^{18}$. The absorbance intensity of minimum localised at $1172 \mathrm{~cm}^{-1}$, attributed to symmetric stretching vibrations of $\mathrm{PO}_{2}^{-}$in $\mathrm{DNA}^{17}$ is slightly decreased in both MCL subtypes, indicating DNA fragmentation associated with apoptotic cell death ${ }^{19}$. The detailed assignments of the minima found in $2^{\text {nd }}$ derivative spectra are shown in Table 1.

Principal component analysis. The PCA results were obtained with three spectral ranges 1720-1495 $\mathrm{cm}^{-1}, 1440-1400 \mathrm{~cm}^{-1}$ and $1360-1160 \mathrm{~cm}^{-1}$ covering spectral features characteristic for proteins, lipids, carbohydrates and nucleic acids functional groups. Initially PCA was performed to differentiate MCL tissues from healthy control and results are presented on Fig. 3a,b. The PC loading plots show the amide band region attributable to proteins (1700-1500 $\mathrm{cm}^{-1}$ ) was heavily loaded for PC1 revealing separation of healthy control from both malignant tissues with $56 \%$ explained variance (green ellipse, Fig. 3a). Spectra of control can be distinguished from MCL tissues by having negative PC1 scores (Fig. 3a), which can be explained by strong positive loading observed at $1630 \mathrm{~cm}^{-1}$ attributed to $\beta$-sheet structures of amide I functional group (Fig. $3 \mathrm{~b}$ ). Positive loadings at $1559 \mathrm{~cm}^{-1}$ and $1541 \mathrm{~cm}^{-1}$, attributable to amide II protein conformers, also separated healthy control cluster from malignant tissues. Moreover, both cancer tissues spectra are separated by positive PC1 scores (purple ellipse, Fig. 3a), explained by strong negative loadings indicated at $1661 \mathrm{~cm}^{-1}$ (amide I) ${ }^{14}, 1566 \mathrm{~cm}^{-1}$ ((COO-) asymmetric stretching vibrations of amide II) ${ }^{20}$ and $1551 \mathrm{~cm}^{-1}$ (amide II $\alpha$-helix structures) ${ }^{20}$ (Fig. 3b). These outcomes suggest that the amide I and II structures are most responsible for discrimination of healthy control from lymphoma tissues, which confirms the conclusions drawn from the examination of the average spectra (Fig. 2). Other differences with an impact on classification involve the negative loadings from rocking vibrations of $\mathrm{CH}_{2}$ of distributed cis-olefins $\left(1419 \mathrm{~cm}^{-1}\right)$ and $\mathrm{C}=\mathrm{O}$ stretching from polysaccharides $\left(1195 \mathrm{~cm}^{-1}, 1167 \mathrm{~cm}^{-1}\right)$ as well as positively loaded peak responsible for symmetric stretching vibrations of $\mathrm{PO}_{2}^{-}\left(1185 \mathrm{~cm}^{-1}\right)$ (Fig. 3b). The PC2 loading plot reveals components mainly responsible for healthy control spectral data dispersion.

Subsequently, PCA was performed including only the lymphoma tissue spectral datasets. Results presented in Fig. $3 c$ reveals separation of spectral clusters of classic (blue ellipse) and aggressive (pink ellipse) MCL. Classic MCL distinction is explained by negative loadings at $1661 \mathrm{~cm}^{-1}, 1641 \mathrm{~cm}^{-1}$ and $1530 \mathrm{~cm}^{-1}$ assignable to amide I 

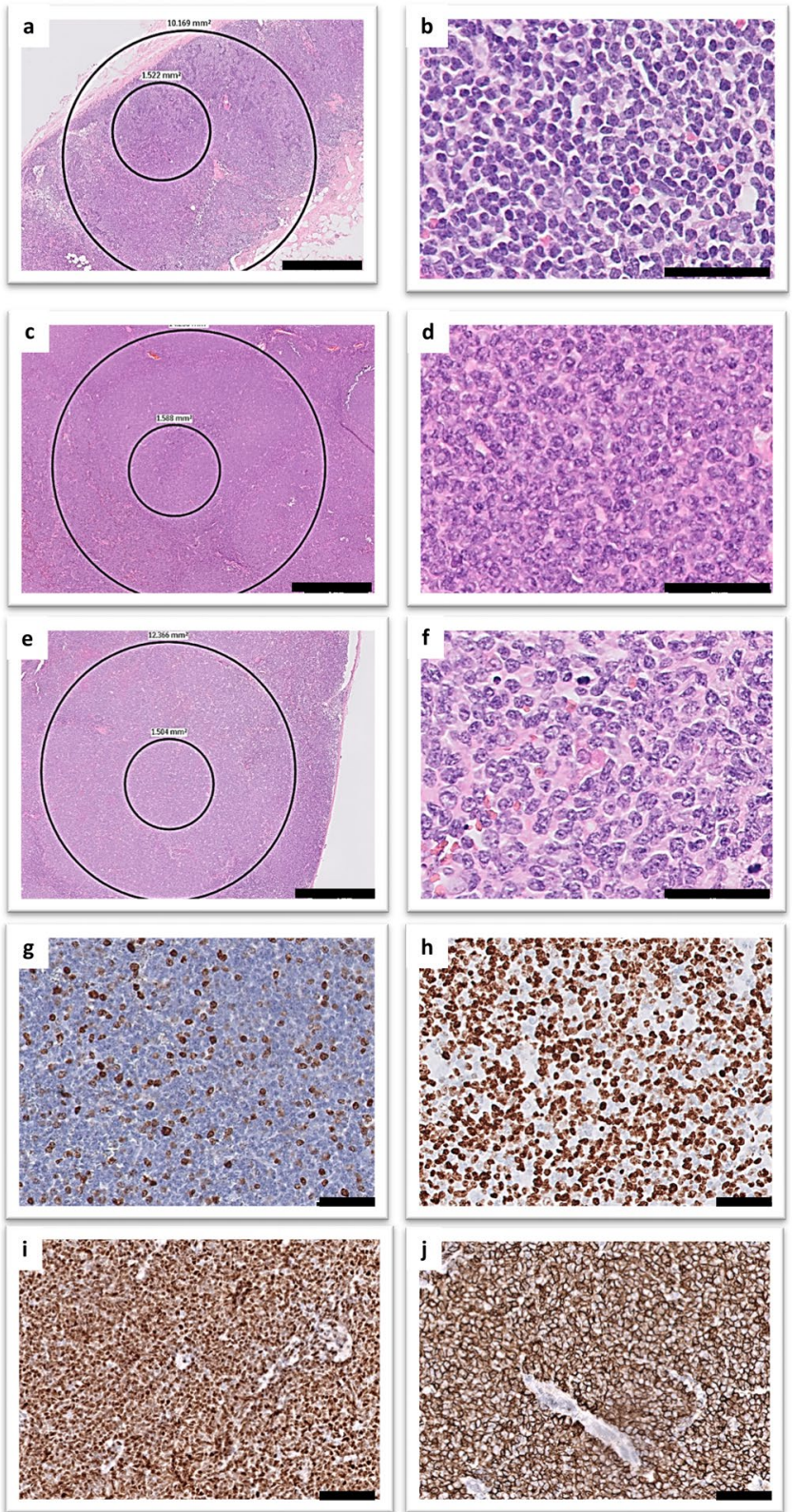

Figure 1. Haematoxylin/eosin histopathological images of representative control and lymphoma tissues. $(\mathbf{a}, \mathbf{b})$ non-neoplastic control lymph node, $(\mathbf{c}, \mathbf{d})$ classic mantle cell lymphoma, $(\mathbf{e}, \mathbf{f})$ and aggressive mantle cell lymphoma. Ki67 proliferation index in (g) classic and (h) aggressive MCL. All MCL cases were positive for cyclin D1 (i) and CD5 (j). Scale bars: $1 \mathrm{~mm}$ in $(\mathbf{a}, \mathbf{c}, \mathbf{e})$ and $50 \mathrm{um}$ in $(\mathbf{b}, \mathbf{d}, \mathbf{f}, \mathbf{g}-\mathbf{j})$.

and II protein conformers (Fig. 3d). Aggressive MCL cluster can be distinguished by positive loadings observed at $1650 \mathrm{~cm}^{-1}, 1624 \mathrm{~cm}^{-1}$ and $1541 \mathrm{~cm}^{-1}$. This outcomes clearly corresponds to changes in absorbance intensity of protein moiety of described average spectra: in the aggressive subtype protein level is higher than in classic MCL (Fig. 2). Of interest is a PC2 positive loading observed at $1647 \mathrm{~cm}^{-1}$ and assigned to $\alpha$-helix amide I structures. This loading seems to be responsible for distinction of spectra obtained from two patients, for whom the treatment was not successful (black ellipse, Fig. 3c).

\section{Discussion}

This research has demonstrated that the histopathological subtyping of MCL into classic and aggressive forms has its strong background in the biochemical landscape of both subtypes. It should be emphasised that this is the first study which has reported the combination of S-FTIR and PCA analysis for the assessment of MCL subtypes. We previously reported the usefulness of the presented approach in distinction of lung cancer subtypes and estimation of chemotherapy efficacy in breast cancer ${ }^{8,9}$.

Our present results showed an absorbance increase in peaks attributed to amide I, amide II and nucleic acids noticed in both malignant tissues, much more pronounced in aggressive MCL. The shift of wavenumber was 
a

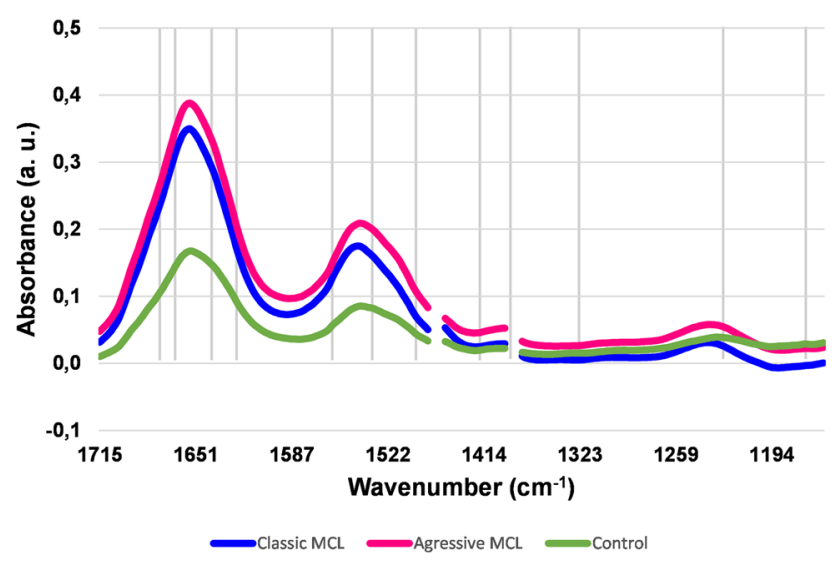

b

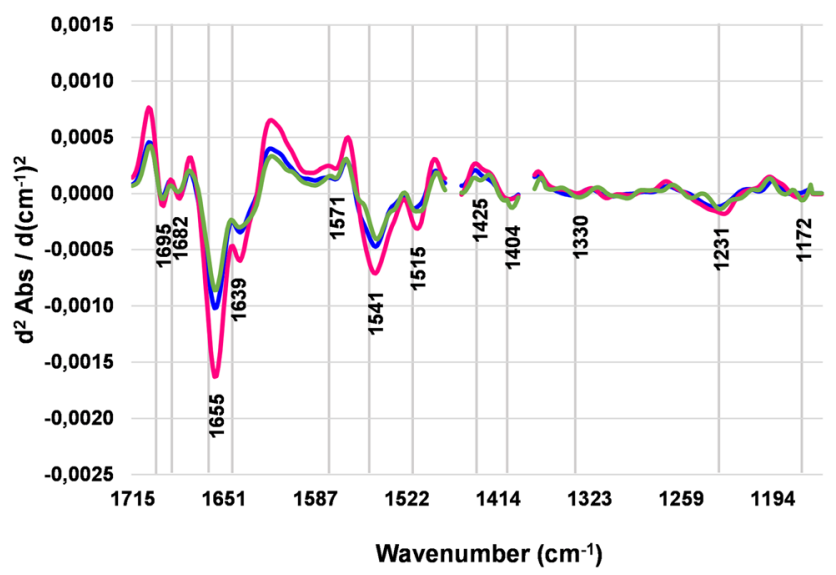

Figure 2. Comparisons of the average absorbance (a) and EMSC-corrected second derivative (b) spectra of the healthy control, classcic MCL and aggressive MCL with assigned minima.

\begin{tabular}{|l|l|l|}
\hline $\begin{array}{l}\text { Band position } \\
\left(\mathbf{c m}^{-1}\right)\end{array}$ & Vibrational mode & References \\
\hline 1695 & Amide I: aggregated $\beta$-sheet & 13 \\
\hline 1682 & Amide I: $\beta$-turn structure & 11 \\
\hline 1655 & Amide I: $\alpha$-helix & 13 \\
\hline 1639 & Amide I: $\beta$-sheet structure & 11 \\
\hline 1571 & $\delta_{\text {as }}(\mathrm{N}-\mathrm{H})$ and $\nu_{\mathrm{s}}(\mathrm{C}-\mathrm{N})$ stretch in amide II & 12 \\
\hline 1541 & $\begin{array}{l}\text { Amide II: } \delta(\mathrm{N}-\mathrm{H}) \text { coupled to } \nu(\mathrm{C}-\mathrm{N}) \text { vibrational modet } \\
\text { AAmide II: perpendicular modes of } \alpha \text {-helix and parallel-chain } \beta \text {-sheet }\end{array}$ & 10,14 \\
\hline 1515 & $\delta(\mathrm{C}-\mathrm{H})$ from tyrosine & 15 \\
\hline 1425 & $\delta_{\text {as }}\left(\mathrm{CH}_{3}\right)$ and $\delta_{\text {as }}\left(\mathrm{CH}_{2}\right)$ of lipids and proteins & 8 \\
\hline 1404 & $\delta\left(\mathrm{CH}_{3}\right)$ of proteins & 13 \\
\hline 1330 & $\delta_{\mathrm{s}}\left(\mathrm{CH}_{3}\right)$ and $\delta_{\mathrm{s}}\left(\mathrm{CH}_{2}\right)$ of lipids and proteins & 10 \\
\hline 1231 & $\nu_{\text {as }}\left(\mathrm{PO}_{2}^{-}\right)$of DNA & 17 \\
\hline 1172 & $\nu_{\mathrm{s}}\left(\mathrm{PO}_{2}^{-}\right)$of DNA & 17 \\
\hline
\end{tabular}

Table 1. Summary of mean values of wavenumbers $\left(\mathrm{cm}^{-1}\right)$ seen in FTIR spectra of classic and aggressive MCL and control tissue. Abbreviations: $\nu_{\mathrm{s}}-$ symmetric stretch; $\nu_{\text {as }}-$ asymmetric stretch; $\delta_{\mathrm{s}}-$ symmetric in-plane deformation (bend); $\delta_{\mathrm{as}}$ - asymmetric in-plane deformation (bend).

observed for $\mathrm{PO}_{2}$ asymmetric stretching vibrations corresponding to DNA. PCA loadings revealed amide I rich in $\beta$-sheet structures and amide II bands mainly differentiate two MCLs. These results correlate with available knowledge about proteins overexpression in the aggressive MCL subtypes. 


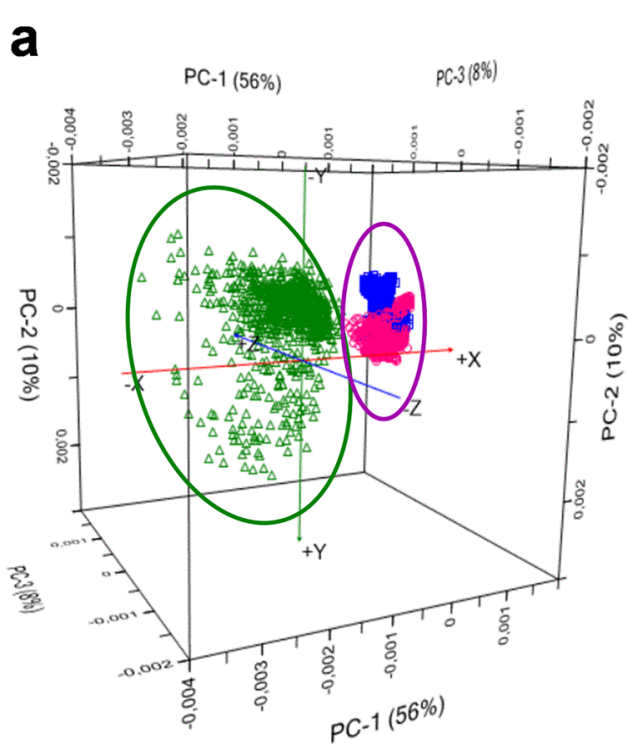

b

$\triangle$ Control

$\square$ Classic MCL

Aggressive $M C L$
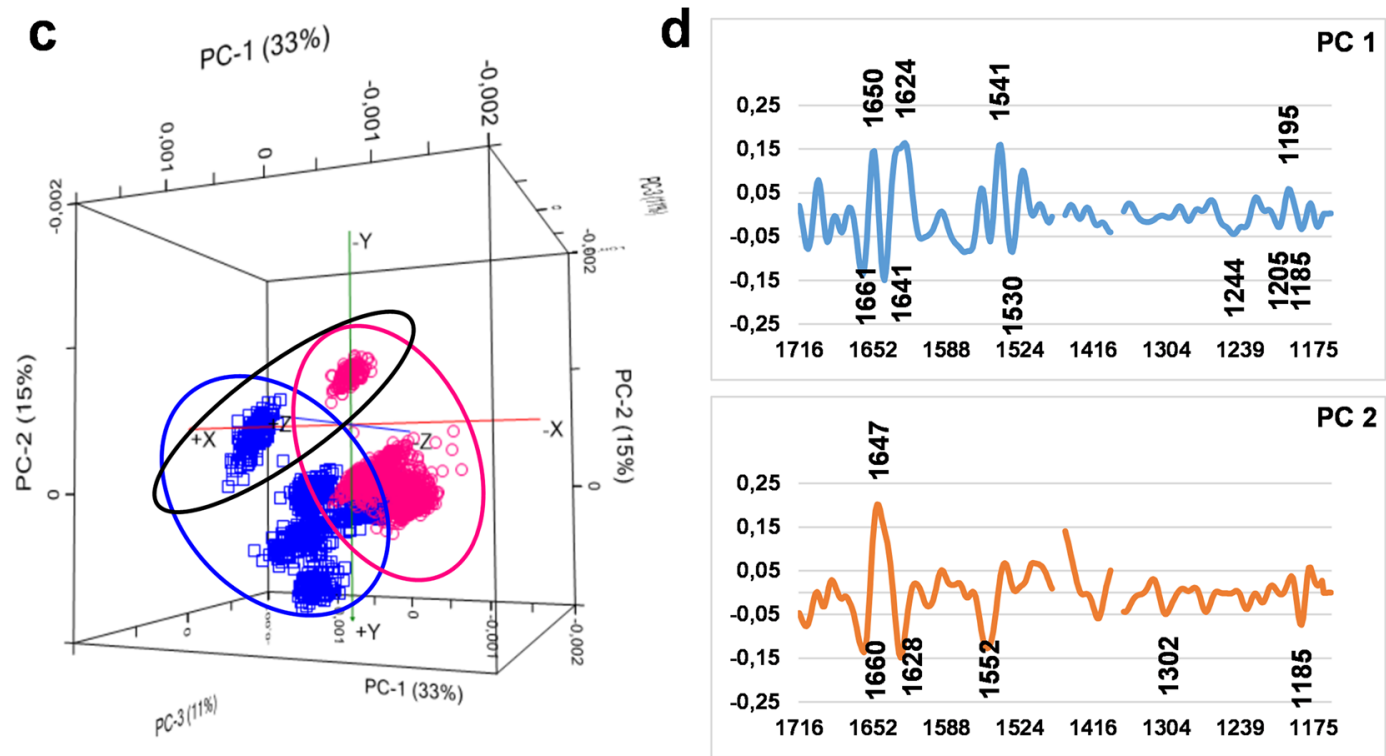

Figure 3. PCA scores (left) and loadings (right) plots showing projections against the first 3 PCs that explain the majority of the spectral variation. (a,b) Control (green ellipse) and both malignant tissues (purple ellipse) spectral datasets, and (c,d) classcic (blue ellipse) and aggressive (pink ellipse) MCL tissues, alone. Black ellipse indicates dead patients.

In conclusion, classic and aggressive MCL are distinct biological and biochemical entities. FTIR spectroscopy was a sensitive tool for the distinction of the biochemical composition of both subtypes and this knowledge may be beneficial for understanding the biology of MCL.

\section{Methods}

Material. The study was conducted under the Institutional Review Board (Protocol No. KBET/6/06/2014) from June 2014 at the University of Rzeszow. The experimental protocols used in this study were approved by the institutional ethics committees (IECs) of the University of Rzeszow and were carried out in accordance with the approved guidelines. Informed consent was obtained from all subjects.

The research was conducted on formalin-fixed paraffin embedded (FFPE) tissue samples that were prepared according to standard protocols. The material was obtained from 18 patients with mantle cell lymphoma. Patients were hospitalised in the Holy Cross Cancer Center in Kielce and examined in the Department of Hematology of 


\begin{tabular}{|c|c|c|c|c|c|c|c|c|c|}
\hline $\begin{array}{l}\text { Case } \\
\text { No. }\end{array}$ & Age & Sex & Histological type & Cyclin D1 & $\begin{array}{l}\text { Ki } 67 \\
\text { index }\end{array}$ & $\begin{array}{l}\text { First-line } \\
\text { treatment }\end{array}$ & Relapse & $\begin{array}{l}\text { Next-line } \\
\text { treatment }\end{array}$ & $\begin{array}{l}\text { Long term } \\
\text { follow-up }\end{array}$ \\
\hline 50 & ND & $\mathrm{F}$ & blastoid/pleomorphic & positive & 90 & RCHOP & ND & ND & ND \\
\hline 6 & 82 & M & blastoid/pleomorphic & positive & 90 & RCHOP & yes & R-Benda & Death \\
\hline 7 & 59 & $\mathrm{~F}$ & blastoid/pleomorphic & negative & 100 & RCHOP & yes & R-Benda & Death \\
\hline 22 & ND & ND & blastoid/pleomorphic & positive & 80 & ND & ND & ND & ND \\
\hline 27 & 70 & $\mathrm{M}$ & blastoid/pleomorphic & positive & $70-80$ & RCHOP & yes & R-Benda & Alive \\
\hline 4 & 76 & $\mathrm{~F}$ & classic & positive & 40 & RCVP & yes & R-Benda & Alive \\
\hline 8 & 70 & $\mathrm{~F}$ & classic & positive & 20 & RCHOP & no & no & Alive \\
\hline 18 & 67 & $\mathrm{M}$ & classic & positive & 30 & ND & ND & ND & ND \\
\hline 21 & 70 & $\mathrm{~F}$ & classic & positive & $20-40$ & RCP & yes & R-Benda & Alive \\
\hline 23 & 86 & M & classic & positive & 20 & ND & ND & ND & ND \\
\hline 25 & 75 & $\mathrm{~F}$ & classic & positive & $40-50$ & RCHOP & yes & Benda & Alive \\
\hline 28 & 68 & M & classic & positive & 50 & RCHOP & no & no & Alive \\
\hline 30 & 86 & M & classic & positive & $30-50$ & R-Benda & no & no & Death \\
\hline 32 & 75 & $\mathrm{~F}$ & classic & positive & $40-50$ & RCHOP & no & no & Death \\
\hline 36 & 88 & $\mathrm{~F}$ & blastoid/pleomorphic & positive & 40 & COP & ND & ND & Death \\
\hline 37 & 83 & $\mathrm{M}$ & blastoid/pleomorphic & positive & 80 & RCOP/RCP & ND & ND & Alive \\
\hline 39 & 70 & $\mathrm{~F}$ & blastoid/pleomorphic & positive & 50 & RCHOP & ND & ND & Death \\
\hline 40 & 76 & M & blastoid/pleomorphic & positive & 90 & RCHOP & ND & ND & Death \\
\hline
\end{tabular}

Table 2. Cliniopathological characteristics of patients with mantle cell lymphoma. (Abbreviations: RCHOP = Rituximab, Cyclophosphamide, Doxorubicin (Hydroxydaunomycin), Vincristine (Oncovin), Prednisolone; RCVP = Rituximab, Cyclophosphamide, Vincristine, Prednisolone; RCP = Rituximab, Cyclophosphamide, Prednisolone; $\mathrm{COP}=$ Cyclophosphamide, Vincristine (Oncovin), Prednisolone; $\mathrm{R}-\mathrm{Benda}=$ Rituximab, Bendamustine; $\mathrm{ND}=$ no data).

\begin{tabular}{|l|l|l|}
\hline Antibody & Clone & Company \\
\hline BCL2 & 124 & DAKO \\
\hline BCL6 & PG-B6p & DAKO \\
\hline BSAP (PAX-5) & DAK-Pax5 & DAKO \\
\hline CD3 & Polyclonal rabbit & DAKO \\
\hline CD5 & 4 C7 & DAKO \\
\hline CD10 & $56 C 6$ & DAKO \\
\hline CD20 & L26 & DAKO \\
\hline CD38 & SP149 & Cell Marque \\
\hline Cyclin D1 & EP12 & DAKO \\
\hline MYC & Y69 & VENTANA \\
\hline Ki-67 & MIB-1 & DAKO \\
\hline MUM-1 & MUM1p & DAKO \\
\hline SOX-11 & MRQ-58 & Cell Marque \\
\hline TdT & EP266 & DAKO \\
\hline
\end{tabular}

Table 3. The list of antibodies used in the immunohistochemical analysis.

Medical University in Lodz between 2009-2018, and treated for MCL with customised chemotherapy. All patients were of white race, eight males, nine females and one unknown. Nine patients were diagnosed with classic MCL and nine patients with aggressive MCL. Clinicopathological characteristics of all MCL patients are presented in Table 2.

Pathological diagnostic approach. The standard panel of antibodies examined in patients with MCL covered CD20, CD3, BCL2, BCL6, MYC, CD10, MUM1, Ki67, cyclin D1, SOX11, TdT, CD5, CD38 and PAX5 (BSAP). The antibodies clones along with the manufacturer are named in Table 3.

Immunohistochemical analysis used monoclonal antibodies [FLEX Monoclonal Mouse Anti-Human, Ready-to-Use (Link), Dako, Denmark] and EnVisionTMFLEX + (Dako, Denmark) for the visualization. The tests were carried out using Autostainer Link 48 (Dako, Denmark).

The H\&E slides were scanned using UltraFast Scanner (Philips IntelliSite Solution, USA) with DigiPath ${ }^{\mathrm{TM}}$ Professional Production Software (Xerox, Norwalk, CT, USA) and representative areas of each case were selected and microtomed into $8 \mu \mathrm{m}$ thick sections and mounted onto $1-\mathrm{mm}$-thick calcium fluoride $\left(\mathrm{CaF}_{2}\right)$ windows (Crystran, UK). 
S-FTIR measurements and spectral analysis. The S-FTIR measurement was performed in transmission mode using a Bruker Vertex V80v FTIR spectrometer coupled with a Hyperion 2000 FTIR microscope (Bruker Optik GmbH, Ettlingen, Germany) equipped with a liquid nitrogen-cooled narrow-band mercury cadmium telluride (MCT) detector, at the Australian Synchrotron IR Microspectroscopy Beamline (Victoria, Australia). The spectral acquisition was performed using a $36 \times$ IR objective (NA =0.50; Bruker Optik GmbH, Ettlingen, Germany) with the aperture size adjusted to $6.9 \mu \mathrm{m}$ diameter beam size, and the spectra were acquired at a $4 \mu \mathrm{m}$ step interval between pixels. The S-FTIR transmission maps were then acquired to cover an area of $200 \mu \mathrm{m} \times$ $200 \mu \mathrm{m}$ on the MCL tissue. For each pixel, the S-FTIR spectrum was recorded within a spectral range of 3800$700 \mathrm{~cm}^{-1}$ using $4-\mathrm{cm}^{-1}$ spectral resolution and 8 co-added scans. In all cases, Blackman-Harris 3-Term apodization, Power-Spectrum phase correction, and zero-filling factor of 2 were set as default acquisition parameters using OPUS 8.0.19 software suite (Bruker). Background spectra were collected from sample-free clean areas on the same $\mathrm{CaF}_{2}$ substrate, following the acquisition of every 50 single spectra of the tissue, using 64 co-added scans and the same default parameters.

Before spectral pre-processing atmospheric compensation function (OPUS 8.0.19 software, Bruker) was applied to remove $\mathrm{CO}_{2}$ and water vapour interference features. FTIR spectra embedded in acquired chemical maps were extracted and pre-processed using CytoSpec ${ }^{\mathrm{TM}}$ version 1.4.02 (Cytospec Inc., Boston, MA, USA) as follows. Prior to Hierarchical Cluster Analysis (HCA), the spectra were quality screened based upon a minimum signal-to-noise $(\mathrm{S} / \mathrm{N})$ ratio of 100 measured over the spectral ranges of $1720-1495 \mathrm{~cm}^{-1}, 1440-1400 \mathrm{~cm}^{-1}$ and $1360-1160 \mathrm{~cm}^{-1}$. Next, quality-screened spectra were pre-processed using noise-reduction algorithm, followed by second derivatization using 13-point Savitzky-Golay algorithm to eliminate the broad baseline offset and curvature and to enhance the features of hidden and overlapping bands. Subsequently, spectra were vector-normalised to account for pathlength differences between samples. HCA based on five clusters was applied on the pre-processed spectra using three spectral regions of $1720-1495 \mathrm{~cm}^{-1}, 1440-1400 \mathrm{~cm}^{-1}$ and $1360-$ $1160 \mathrm{~cm}^{-1}$ to exclude the paraffin bands typically found at $2920 \mathrm{~cm}^{-1}, 2850 \mathrm{~cm}^{-1}, 1470 \mathrm{~cm}^{-1}$ and $1465 \mathrm{~cm}^{-1}[10]$. As a result, obtained average absorbance and second derivative spectra were used for cluster selection for further analysis.

Principal component analysis (PCA) was performed using The Unscrambler ${ }^{\circledR} 10.4$ software package (CAMO Software AS, Oslo, Norway). Prior to PCA selected representative second derivative spectra were corrected using Extended Multiplicative Scatter Correction (EMSC) in order to correct spectral artefacts commonly found in FTIR spectra of biological samples. The PCA approach was first applied to three individual groups: healthy control, classic MCL and aggressive MCL to eliminate outliers from samples in the same group.

After the selection of representative spectra, the EMSC-normalised second derivative spectral datasets of all groups were combined into one single set. PCA was subsequently performed on the entire combined dataset to investigate similarities and differences of biochemical makeups between healthy and malignant tissues. To exclude the bands associated with paraffin, the PCA was calculated using three spectral regions of 1720-1495 $\mathrm{cm}^{-1}, 1440-1400 \mathrm{~cm}^{-1}$ and $1360-1160 \mathrm{~cm}^{-1}$.

\section{Data Availability}

For original data, please contact izazawlik@yahoo.com.

\section{References}

1. Perez-Galan, P., Dreyling, M. \& Wiestner, A. Mantle cell lymphoma: biology, pathogenesis, and the molecular basis of treatment in the genomic era. Blood 117, 26-38, https://doi.org/10.1182/blood-2010-04-189977 (2011).

2. Dreyling, M. et al. Newly diagnosed and relapsed mantle cell lymphoma: ESMO Clinical Practice Guidelines for diagnosis, treatment and follow-up. Annals of Oncology 28, 62-71, https://doi.org/10.1093/annonc/mdx223 (2017).

3. Swerdlow, S. et al. WHO Classification of Tumours of Haematopoietic and Lymphoid Tissues (Revised 4th edition). (IARC Press, 2017).

4. Campo, E. \& Rule, S. Mantle cell lymphoma: evolving management strategies. Blood 125, 48-55, https://doi.org/10.1182/ blood-2014-05-521898 (2015).

5. Bernard, M. et al. Blastic variant of mantle cell lymphoma: a rare but highly aggressive subtype. Leukemia 15, 1785-1791, https://doi. org/10.1038/sj.leu.2402272 (2001).

6. Hernandez, L. et al. p53 gene mutations and protein overexpression are associated with aggressive variants of mantle cell lymphomas. Blood 87, 3351-3359 (1996).

7. Halldorsdottir, A. et al. Impact of TP53 mutation and 17p deletion in mantle cell lymphoma. Leukemia 25, 1904-1908, https://doi. org/10.1038/leu.2011.162 (2011).

8. Zawlik, I. et al. FPA-FTIR Microspectroscopy for Monitoring Chemotherapy Efficacy in Triple-Negative Breast Cancer. Scientific Reports 6, https://doi.org/10.1038/srep37333 (2016).

9. Kaznowska, E. et al. The classification of lung cancers and their degree of malignancy by FTIR, PCA-LDA analysis, and a physicsbased computational model. Talanta 186,337-345, https://doi.org/10.1016/j.talanta.2018.04.083 (2018).

10. Timilsena, Y. et al. Investigation of oil distribution in spray-dried chia seed oil microcapsules using synchrotron-FTIR microspectroscopy. Food Chemistry 275, 457-466, https://doi.org/10.1016/j.foodchem.2018.09.04S (2019).

11. Tanthanucha, W., Thumanu, K., Lorthongpanich, C., Parnpai, R. \& Heraud, P. Neural differentiation of mouse embryonic stem cells studied by FTIR spectroscopy. Journal of Molecular Structure 967, 189-195, https://doi.org/10.1016/j.molstruc.2010.01.007 (2010).

12. Grzelak, M. et al. Diagnosis of ovarian tumour tissues by SR-FTIR spectroscopy: A pilot study. Spectrochimica Acta Part a-Molecular and Biomolecular Spectroscopy 203, 48-55, https://doi.org/10.1016/j.saa.2018.05.070 (2018).

13. Vongsvivut, J. et al. FTIR microspectroscopy for rapid screening and monitoring of polyunsaturated fatty acid production in commercially valuable marine yeasts and protists. Analyst 138, 6016-6031, https://doi.org/10.1039/c3an00485f (2013).

14. Movasaghi, Z., Rehman, S. \& Rehman, I. Fourier transform infrared (FTIR) spectroscopy of biological tissues. Applied Spectroscopy Reviews 43, 134-179, https://doi.org/10.1080/05704920701829043 (2008).

15. Wongwattanakul, M. et al. Classification of Gemcitabine resistant Cholangiocarcinoma cell lines using synchrotron FTIR microspectroscopy. Journal of Biophotonics 10, 367-376, https://doi.org/10.1002/jbio.201500253 (2017).

16. Sander, B. et al. Mantle cell lymphoma-a spectrum from indolent to aggressive disease. Virchows Archiv 468, 245-257, https://doi. org/10.1007/s00428-015-1840-6 (2016). 
17. Gazi, E. et al. A study of cytokinetic and motile prostate cancer cells using synchrotron-based FTIR microspectroscopic imaging. Vibrational Spectroscopy 38, 193-201, https://doi.org/10.1016/j.vibspec.2005.02.026 (2005).

18. Khoury, J. et al. Cytogenetic findings in blastoid mantle cell lymphoma. Human Pathology 34, 1022-1029, https://doi.org/10.1053/ S0046-8177(03)00412-X (2003)

19. Siriwarin, B., Weerapreeyakul, N., Tanthanuch, W. \& Thumanu, K. Biomolecular changes and DNA targeting effect of sesamol in human lung adenocarcinoma (SK-LU-1) cells by FTIR microscopy. Asian Pacific Journal of Tropical Biomedicine 8, 377-386, https:// doi.org/10.4103/2221-1691.239425 (2018).

20. Olsztynska-Janus, S., Pietruszka, A., Kielbowicz, Z. \& Czarnecki, M. ATR-IR study of skin components: Lipids, proteins and water. Part I: Temperature effect. Spectrochimica Acta Part a-Molecular and Biomolecular Spectroscopy 188, 37-49, https://doi.org/10.1016/j. saa.2017.07.001 (2018).

\section{Acknowledgements}

We thank Synevo Sp. z o.o. Company (HQ, Warsaw, Poland) for providing the access to UltraFast Scanner and DigiPath $^{\mathrm{TM}}$ Professional Production Software. The S-FTIR spectral images of all tissue samples used in this study was acquired using an online Bruker Vertex V80v FTIR spectrometer coupled with a Hyperion 2000 FTIR microscope system at Infrared Microspectroscopy (IRM) beamline at Australian Synchrotron (Victoria, Australia). The study was financially supported by University of Rzeszow, Faculty of Medicine. The study was partly performed within the project 'Centre for Innovative Research in Medical and Natural Sciences', which was supported by University of Rzeszow, and was co-financed within Regional Operational Programme for Podkarpackie Province for 2007-2013 (Contract Number: UDA-RPPK.01.03.00-18-004/12-00).

\section{Author Contributions}

M.K. designed the project and analyzed and discussed the data. D.J.K. and M.B. designed the project and prepared samples. J.K. prepared samples. V.A. and S.S. performed experiment at Australian Synchrotron. J.C. designed the project and analyzed and discussed the data. M.C. designed the project and analyzed and discussed the data. P.H. designed the project. M.T. and J.V. designed the project, performed experiment at Australian Synchrotron and analyzed and discussed the data. I.Z. designed the project and analyzed and discussed the data. All authors prepared final manuscript.

\section{Additional Information}

Supplementary information accompanies this paper at https://doi.org/10.1038/s41598-019-49326-3.

Competing Interests: The authors declare no competing interests.

Publisher's note: Springer Nature remains neutral with regard to jurisdictional claims in published maps and institutional affiliations.

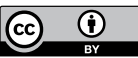

Open Access This article is licensed under a Creative Commons Attribution 4.0 International License, which permits use, sharing, adaptation, distribution and reproduction in any medium or format, as long as you give appropriate credit to the original author(s) and the source, provide a link to the Creative Commons license, and indicate if changes were made. The images or other third party material in this article are included in the article's Creative Commons license, unless indicated otherwise in a credit line to the material. If material is not included in the article's Creative Commons license and your intended use is not permitted by statutory regulation or exceeds the permitted use, you will need to obtain permission directly from the copyright holder. To view a copy of this license, visit http://creativecommons.org/licenses/by/4.0/.

(C) The Author(s) 2019 